\title{
FERTILIZANTE ORGÂNICO COMO FONTE DE FÓSFORO NO CULTIVO INICIAL DE Brachiaria brizantha CV. MARANDÚ ${ }^{1}$
}

\author{
Ornã Enisson Almeida Ourives ${ }^{2}$, Gustavo Maia Souza ${ }^{2}$, Carlos Sérgio Tiritan², Diego Henriques Santos ${ }^{3}$
}

\begin{abstract}
ORGANIC FERTILIZER AS PHOSPHORUS

SUPPLIER FOR Brachiaria brizantha CV. MARANDÚ

Phosphorus is considered an essential element for plants, but it is found in low amounts in Brazilian soils, mainly in areas destined to pastures, and the application of organic matter contributes to the improvement of physical, chemical and biological soil attributes. The research had the objective of evaluating the application effects of the Bokashi organic compound on soil macro and micronutrients contents and leaves, as well as on Brachiaria brizantha cv. Marandú dry mass yield, evaluating the potential of the organic fertilizer as phosphorus source, in comparison with conventional chemical fertilizers. Different organic compound doses supplied the

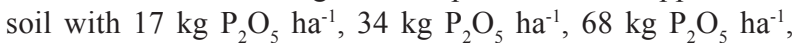
$136 \mathrm{~kg} \mathrm{P}_{2} \mathrm{O}_{5} \mathrm{ha}^{-1}$, and $204 \mathrm{~kg} \mathrm{P}_{2} \mathrm{O}_{5}$ ha $^{-1}$, comparing it with the conventional chemical fertilizer and the control. The results revealed that the organic fertilizer Bokashi can adequately replace the conventional chemical fertilizer of Brachiaria brizantha cv. Marandú, supplying the soil and plant with appropriate nutrients levels and maintaining the dry mass yield.
\end{abstract}

KEY-WORDS: Organic matter; organic fertilizers; plants mineral nutrition; Bokashi.

\section{INTRODUÇÃO}

O Marandú (Brachiaria brizhanta cv. Marandú) é uma gramínea forrageira, de hábito de crescimento cespitoso, formando touceiras de até 1,0 m de diâmetro e perfilhos com altura de até 1,5 m. De acordo com Costa et al. (2001), suas raízes são profundas, o que favorece sua sobrevivência durante períodos longos de estiagem. Originária da África Tropical, encontra-se amplamente difundida nos países tropicais, incluindo o Brasil. As plantas deste gênero, segundo Alcântara \& Bufarah (1999),

\section{RESUMO}

O fósforo é considerado elemento essencial para as plantas, mas é encontrado em baixas quantidades nos solos brasileiros, principalmente em áreas destinadas a pastagens, e a aplicação de matéria orgânica contribui para a melhoria dos atributos físicos, químicos e biológicos do solo. O trabalho teve por objetivo avaliar os efeitos da aplicação do composto orgânico Bokashi sobre os teores de macro e micronutrientes do solo e nas folhas, além da produção de massa seca da Brachiaria brizantha cv. Marandú, avaliando o potencial do adubo orgânico como fonte de fósforo, em comparação à adubação química convencional. Foram aplicadas diferentes doses do composto orgânico, fornecendo ao solo $17 \mathrm{~kg} \mathrm{P}_{2} \mathrm{O}_{5} \mathrm{ha}^{-1}, 34 \mathrm{~kg} \mathrm{P}_{2} \mathrm{O}_{5} \mathrm{ha}^{-1}$, $68 \mathrm{~kg} \mathrm{P}_{2} \mathrm{O}_{5}$ ha $^{-1}, 136 \mathrm{~kg} \mathrm{P}_{2} \mathrm{O}_{5}$ ha $^{-1}$ e $204 \mathrm{~kg} \mathrm{P}_{2} \mathrm{O}_{5}$ ha $^{-1}$, comparando-o com a adubação química convencional e o tratamento testemunha. Os resultados revelaram que o adubo orgânico Bokashi pode substituir, de forma viável, a adubação química convencional da Brachiaria brizantha cv. Marandú, suprindo o solo e a planta com níveis adequados de nutrientes e mantendo a produção de massa seca.

PALAVRAS-CHAVE: Matéria orgânica; adubação orgânica; nutrição mineral de plantas; Bokashi.

adaptam-se a variadas condições de solo e clima, mas sua expansão deveu-se, principalmente, à sua adaptação a condições de solos com baixa e média fertilidade, nas quais proporciona produção satisfatória de forragem.

Características físico-químicas desfavoráveis dos latossolos e neossolos, como baixa disponibilidade de fósforo, restringem o estabelecimento de forrageiras de alta produtividade, como o capim Elefante, capim Mombaça e o capim Marandú. Na prática, é comum o estabelecimento de espécies forrageiras em solos com baixa disponibilidade de

1. Trabalho recebido em dez./2008 e aceito para publicação em jun./2010 (nº registro: PAT 5138/ DOI: 10.5216/pat.v40i2.5138).

2. Universidade do Oeste Paulista (Unoeste), Faculdade de Ciências Agrárias, Presidente Prudente, SP, Brasil.

E-mails: ornaenisson@yahoo.com.br, gustavo@unoeste.br, tiritan@unoeste.br.

3. Universidade Estadual Paulista (Unesp), Faculdade de Ciências Agrárias, Botucatu, SP, Brasil.

E-mail: diego@fca.unesp.br. 
fósforo, resultando em baixo perfilhamento e baixa produção de massa seca. Diversos autores, dentre eles Guss et al. (1990) e Hoffmann et al. (1995), registraram aumento na produção de matéria seca (MS) de forrageiras, em reposta a doses de fósforo.

O fósforo é um importante macronutriente, componente estrutural de macromoléculas, como ácidos nucléicos e fosfolipídeos, e, também, da adenosina trifosfato (ATP). É considerado elemento essencial para as plantas e encontra-se em baixa quantidade nos solos brasileiros, de maneira que os solos, por serem acentuadamente intemperizados, apresentam capacidade de troca catiônica (CTC) reduzida e adsorção aniônica alta. Esta condição proporciona redução na saturação de bases, com aumento gradual na retenção de ânions, como o fosfato, sulfato e molibdato, entre outros. Em decorrência disto, os solos mudam, gradualmente, de fonte para dreno de fósforo inorgânico (Novais \& Smyth 1999).

Segundo Loganathan \& Fernando (1980), quando adiciona-se uma fonte solúvel de fósforo a determinado solo, mais de $90 \%$ do total aplicado é adsorvido na primeira hora de contato com o solo. Novais et al. (1980) também relatam que o maior tempo de contato solo-fosfato causa sua maior solubilidade, ocasionando menor disponibilidade de fósforo para as plantas. A deficiência de fósforo é problemática, pois reduz a absorção de nitrogênio, como demonstrado em diversos trabalhos (Lee 1982, Rufty et al. 1993, Schjorring 1996).

O uso de fertilizantes orgânicos é uma ferramenta fundamental na recuperação de solos degradados e na produção agrícola, pois são grandes os efeitos benéficos sobre as propriedades químicas, físicas, físico-químicas e biológicas do solo. Segundo Kiehl (1985), a fertilidade do solo pode ser elevada pelo uso de fertilizantes minerais, corretivos e fertilizantes orgânicos. No entanto, os fertilizantes minerais e os corretivos, embora aumentem a disponibilidade de nutrientes às culturas, têm pequena contribuição na melhoria das propriedades físicas e biológicas, quando comparados aos fertilizantes orgânicos.

A fertilidade do solo é resultado da combinação de fatores físicos, químicos e biológicos e a matéria orgânica interfere em todos estes fatores. Segundo Lopes \& Theodoro (1998), as propriedades coloidais do húmus, relacionadas à agregação das partículas, conferem estabilidade estrutural ao solo. Por consequência, formam-se macro e microporos, responsáveis pela aeração e pela capacidade de re- tenção de água. As propriedades químicas do húmus são representadas, principalmente, pelo fornecimento de nutrientes essenciais; interação com as argilas, formando o complexo argilo-húmico, responsável pela melhoria da capacidade de troca cationnica; poder complexante sobre metais; ação sobre a disponibilidade do fósforo; e ação estabilizante sobre variações ambientais no solo, como modificações no $\mathrm{pH}$, temperatura e teor de umidade, gás carbônico e oxigênio, entre outros (Kiehl 1985). Particularmente, o aumento da disponibilidade de fósforo, em função da redução de sua adsorção às argilas, tem sido alvo de grande interesse (Haynes 1984, Afif et al. 1995, Kirk 1999, Andrade et al. 2003, David et al. 2008, Matos 2008).

Bokashi é a definição japonesa para todo composto de origem orgânica. Devido à sua composição muito rica em matéria orgânica, proporciona ao solo uma série de vantagens, entre elas a melhoria da estrutura do solo. O Bokashi é fermentado em um conjunto de mais de 10 gêneros e 90 espécies de diferentes micro-organismos, que vivem no solo naturalmente fértil, entre eles leveduras, actinomicetos e bactérias lácticas (Fornari 2002). Segundo Costa (1987), cada grupo de micro-organismos desempenha uma função no solo, melhorando a capacidade de produção das plantas, pois confere a elas maior resistência aos agentes patogênicos existentes no solo e maior disponibilidade de elementos necessários ao crescimento.

Neste contexto, objetivou-se, com este trabalho, avaliar os efeitos da aplicação do composto orgânico Bokashi sobre os teores de nutrientes do solo e foliares e sobre a massa seca da Brachiaria brizantha cv. Marandú, avaliando o potencial do adubo orgânico como fonte de fósforo, em comparação com a adubação química convencional. Uma vez que as fontes químicas de fósforo possuem baixa eficiência em solos tropicais, a intenção foi verificar se o Bokashi, fonte orgânica de fósforo, possui maior eficiência, por sofrer menor fixação.

\section{MATERIAL E MÉTODOS}

O experimento foi conduzido sob condições de campo, em área experimental localizada no município de Teodoro Sampaio (52 10 '03'S, 22³1'57'W e $430 \mathrm{~m}$ de altitude), Estado de São Paulo, de outubro de 2007 a fevereiro de 2008. O clima da região, segundo a classificação de Köppen, é do tipo Cwa, que é 
caracterizado por apresentar clima tropical com estação chuvosa e quente bem definida, entre os meses de setembro e março, e inverno seco, com temperaturas amenas, entre os meses de abril e setembro.

O solo foi caracterizado, segundo Embrapa (2006), como Latossolo Vermelho com textura franco-areno-argilosa, com relevo suave e ondulado e boa drenagem. Foram coletadas amostras para caracterização de atributos químicos e granulométricos (Embrapa 1997), na camada $0-0,20 \mathrm{~m}$, com os seguintes resultados: $\mathrm{pH}$ em água de 6,$6 ; 13,5 \mathrm{~g} \mathrm{dm}^{-3} \mathrm{de}$ MO; 54,75 mg dm${ }^{-3}$ de P (Mehlich); 1,0 $\mathrm{mmol}_{\mathrm{c}} \mathrm{dm}^{-3}$ de $\mathrm{K} ; 12,5 \mathrm{mmol}_{\mathrm{c}} \mathrm{dm}^{-3} \mathrm{de} \mathrm{Ca} ; 5,75 \mathrm{mmol}_{\mathrm{c}} \mathrm{dm}^{-3} \mathrm{de}$ $\mathrm{Mg} ; 31,5 \mathrm{mmol}_{\mathrm{c}} \mathrm{dm}^{-3} \mathrm{de} \mathrm{CTC} ; 60 \%$ de saturação por bases (V\%); $620 \mathrm{~g} \mathrm{~kg}^{-1}$ de areia; $90 \mathrm{~g} \mathrm{~kg}^{-1}$ de silte; e $290 \mathrm{~g} \mathrm{~kg}^{-1}$ de argila.

Cada parcela experimental constou de quatro linhas de sete metros de comprimento, espaçadas em 1,0 m, desprezando-se as bordaduras. Adotou-se o delineamento experimental em blocos ao acaso, com sete tratamentos e quatro repetições, totalizando 28 parcelas. Os tratamentos constaram de doses do fertilizante orgânico Bokashi (250 $\mathrm{g} \mathrm{m}^{-2} ; 500 \mathrm{~g} \mathrm{~m}^{-2}$; $1.000 \mathrm{~g} \mathrm{~m}^{-2} ; 2.000 \mathrm{~g} \mathrm{~m}^{-2}$; e $3.000 \mathrm{~g} \mathrm{~m}^{-2}$ ), fornecendo, respectivamente, $17 \mathrm{~kg} \mathrm{P}_{2} \mathrm{O}_{5} \mathrm{ha}^{-1} ; 34 \mathrm{~kg} \mathrm{P}_{2} \mathrm{O}_{5} \mathrm{ha}^{-1}$; $68 \mathrm{~kg} \mathrm{P}_{2} \mathrm{O}_{5}$ ha $^{-1} ; 136 \mathrm{~kg} \mathrm{P}_{2} \mathrm{O}_{5}$ ha $^{-1}$; e $204 \mathrm{~kg} \mathrm{P}_{2} \mathrm{O}_{5}$ ha $^{-1}$, além de dois tratamentos controles, sendo o primeiro adubado quimicamente $\left(100 \mathrm{~kg}\right.$ de $\mathrm{P}_{2} \mathrm{O}_{5}$ ha $^{-1}$, no plantio, e $50 \mathrm{~kg}$ de $\mathrm{N}$ e $100 \mathrm{~kg}$ de $\mathrm{K}_{2} \mathrm{O} \mathrm{ha}^{-1}$, aos 30 dias após o plantio) e o segundo sem adubação (testemunha).

O adubo orgânico Bokashi foi preparado conforme recomendação de Costa (1987), sendo composto por húmus de minhoca $(50 \%)$, esterco de aves $(12 \%)$, farinha de ossos (5\%), farelo de arroz $(10 \%)$, farelo de algodão $(10 \%)$, yoorin $(8 \%)$, pó de rocha $(5 \%)$, cinzas $(3 \%)$ e inoculante E.M. $(0,1 \%)$. Antes do início do experimento, foi realizada a caracterização química do adubo, que apresentou a seguinte composição: $\mathrm{pH}\left(\mathrm{CaCl}_{2} 1 \mathrm{~mol} \mathrm{~L}^{-1}\right) 6,5$; 5,25\% de umidade; $46,96 \%$ de $\mathrm{MO} ; 13,7 \mathrm{~g} \mathrm{~kg}^{-1} \mathrm{de}$ $\mathrm{N} ; 3,0 \mathrm{~g} \mathrm{~kg}^{-1}$ de P; $0,4 \mathrm{~g} \mathrm{~kg}^{-1}$ de $\mathrm{K}$; $6,6 \mathrm{~g} \mathrm{~kg}^{-1}$ de Ca; $3,9 \mathrm{~g} \mathrm{~kg}^{-1}$ de $\mathrm{Mg} ; 1,5 \mathrm{~g} \mathrm{~kg}^{-1}$ de $\mathrm{S} ; 42 \mathrm{mg} \mathrm{kg}^{-1}$ de $\mathrm{Cu}$; $436 \mathrm{mg} \mathrm{kg}^{-1}$ de Mn; $56 \mathrm{mg} \mathrm{kg}^{-1}$ de Zn; e $7696 \mathrm{mg} \mathrm{kg}^{-1}$ de Fe.

A adubação orgânica foi realizada no momento da semeadura da Brachiaria brizantha cv. Marandú ( $8 \mathrm{~kg}$ de sementes viáveis por hectare). Aos 60 dias após a semeadura, realizou-se análise da produção de matéria seca, análise química do solo e diagno- se foliar. Para avaliação do teor de matéria seca, realizou-se amostragem com quadro de madeira de $1,0 \mathrm{~m}^{2}$, sendo o corte da forrageira realizado a $10 \mathrm{~cm}$ da superficie do solo. Para a diagnose foliar, amostras de 500 gramas de massa fresca foliar foram enviadas ao Laboratório de Tecidos Vegetais da Universidade do Oeste Paulista, para secagem em estufa de aeração forçada, à temperatura de $65^{\circ} \mathrm{C}$, até se obter massa constante. As amostras correspondentes a cada parcela foram moídas em moinhos tipo Wiley, para determinação das concentrações de N, P, K, Ca, Mg, $\mathrm{S}$ e micronutrientes, segundo metodologia proposta por Malavolta et al. (1997). Uma amostra composta por três subamostras de solo por parcela foi coletada, à profundidade de $20 \mathrm{~cm}$, para determinação dos atributos químicos, seguindo metodologia de Raij et al. (2001).

Os dados obtidos foram submetidos a análise de variância e, quando o teste $\mathrm{F}$ foi significativo, procedeu-se à comparação de médias dos tratamentos, pelo teste Tukey $(\mathrm{p}>0,05)$.

\section{RESULTADOS E DISCUSSÃO}

Em relação às análises químicas do solo, não foram observadas diferenças significativas entre os tratamentos, para as médias de $\mathrm{pH}, \mathrm{CTC}, \mathrm{V} \%$ e teores de $\mathrm{Ca}, \mathrm{K}, \mathrm{Mn}$ e $\mathrm{Cu}$ (Tabela 1). Para as demais variáveis ( $\mathrm{MO}, \mathrm{Mg}, \mathrm{P}, \mathrm{S}, \mathrm{Fe}, \mathrm{Zn}$ e $\mathrm{B})$, diferenças significativas foram verificadas entre as médias dos tratamentos testados (Tabela 1).

Em relação à matéria orgânica, observou-se elevação dos teores no solo, conforme elevação dos teores de Bokashi, ou seja, a matéria orgânica foi influenciada, significativamente, pelas doses de Bokashi aplicadas ao solo, sendo que a adubação com $2.000 \mathrm{~g} \mathrm{~m}^{-2}$ (T4) proporcionou as maiores médias, superiores à obtida com a adubação química convencional. O tratamento testemunha (T0) e o tratamento convencional (TC) não diferiram entre si. Já em relação ao teor de magnésio no solo, a dose de $3.000 \mathrm{~g} \mathrm{~m}^{-2}$ (T5) apresentou os melhores resultados, enquanto os tratamentos T0 e TC não diferiram entre si (Tabela 1).

Com relação ao fósforo, observou-se elevação dos teores de fósforo no solo, conforme elevação dos terores de Bokashi, sendo que o tratamento T4 apresentou os melhores resultados, superiores aos obtidos com a adubação fosfatada convencional. Já em relação ao teor de ferro no solo, o tratamento T5 
Tabela 1. Teores médios de pH, MO, CTC, V\%, macro e micronutrientes quantificados na análise de solo, 60 dias após a fertilização com fertilizante orgânico e mineral (Teodro Sampaio, SP, 2008).

\begin{tabular}{lccccccc}
\hline \multicolumn{1}{c}{ Tratamentos } & $\mathrm{T} 0$ & $\mathrm{~T} 1$ & $\mathrm{~T} 2$ & $\mathrm{~T} 3$ & $\mathrm{~T} 4$ & $\mathrm{~T} 5$ & $\mathrm{TC}$ \\
\hline $\mathrm{pH}$ & 6,85 & 6,80 & 6,75 & 6,85 & 6,75 & 6,62 & 6,77 \\
$\mathrm{MO}\left(\mathrm{g} \mathrm{dm}^{-3}\right)$ & $13,50 \mathrm{~b}$ & $16,50 \mathrm{~b}$ & $16,50 \mathrm{~b}$ & $18,00 \mathrm{ab}$ & $23,50 \mathrm{a}$ & $22,25 \mathrm{ab}$ & $15,75 \mathrm{~b}$ \\
$\mathrm{Ca}\left(\mathrm{mmol}_{\mathrm{c}} \mathrm{dm}^{-3}\right)$ & 12,50 & 13,00 & 12,00 & 7,00 & 8,75 & 14,25 & 7,50 \\
$\mathrm{Mg}\left(\mathrm{mmol}_{\mathrm{c}} \mathrm{dm}^{-3}\right)$ & $5,75 \mathrm{ab}$ & $7,50 \mathrm{ab}$ & $5,25 \mathrm{ab}$ & $3,25 \mathrm{~b}$ & $5,25 \mathrm{ab}$ & $11,75 \mathrm{a}$ & $5,75 \mathrm{ab}$ \\
$\mathrm{K}\left(\mathrm{mmol}_{\mathrm{c}} \mathrm{dm}^{-3}\right)$ & 1,00 & 0,92 & 0,92 & 0,62 & 0,95 & 1,30 & 0,97 \\
$\mathrm{CTC}\left(\mathrm{mmol}_{\mathrm{c}} \mathrm{dm}^{-3}\right)$ & 31,50 & 33,50 & 31,75 & 24,25 & 29,00 & 42,00 & 27,50 \\
$\mathrm{P}\left(\mathrm{mg} \mathrm{dm}^{-3}\right)$ & $54,75 \mathrm{~b}$ & $83,00 \mathrm{~b}$ & $159,70 \mathrm{ab}$ & $211,75 \mathrm{a}$ & $236,50 \mathrm{a}$ & $156,25 \mathrm{ab}$ & $131,50 \mathrm{ab}$ \\
$\mathrm{S}\left(\mathrm{mg} \mathrm{dm}^{-3}\right)$ & $1,15 \mathrm{c}$ & $1,00 \mathrm{c}$ & $3,60 \mathrm{bc}$ & $3,47 \mathrm{bc}$ & $6,10 \mathrm{~b}$ & $9,17 \mathrm{a}$ & $1,40 \mathrm{c}$ \\
$\mathrm{Mn}\left(\mathrm{mg} \mathrm{dm}^{-3}\right)$ & 59,40 & 50,65 & 63,10 & 62,92 & 69,25 & 64,80 & 68,47 \\
$\mathrm{Fe}\left(\mathrm{mg} \mathrm{dm}^{-3}\right)$ & $11,75 \mathrm{~b}$ & $12,12 \mathrm{~b}$ & $15,25 \mathrm{ab}$ & $15,25 \mathrm{ab}$ & $19,02 \mathrm{a}$ & $20,57 \mathrm{a}$ & $12,92 \mathrm{~b}$ \\
$\mathrm{Cu}\left(\mathrm{mg} \mathrm{dm}^{-3}\right)$ & 0,80 & 0,97 & 1,17 & 1,30 & 1,60 & 2,02 & 3,22 \\
$\mathrm{Zn}\left(\mathrm{mg} \mathrm{dm}^{-3}\right)$ & $2,50 \mathrm{~d}$ & $3,70 \mathrm{~cd}$ & $6,42 \mathrm{~cd}$ & $7,5 \mathrm{bc}$ & $11,70 \mathrm{ab}$ & $14,75 \mathrm{a}$ & $5,60 \mathrm{~cd}$ \\
$\mathrm{~B}\left(\mathrm{mg} \mathrm{dm}^{-3}\right)$ & $0,13 \mathrm{~b}$ & $0,24 \mathrm{ab}$ & $0,13 \mathrm{~b}$ & $0,13 \mathrm{~b}$ & $0,14 \mathrm{~b}$ & $0,20 \mathrm{ab}$ & $0,42 \mathrm{a}$ \\
$\mathrm{V} \%$ & 60,20 & 62,70 & 55,70 & 44,00 & 49,25 & 59,50 & 49,50 \\
\hline
\end{tabular}

$\mathrm{T} 0=$ testemunha; $\mathrm{T} 1=250 \mathrm{~g} \mathrm{~m}^{-2}$ de Bokashi; $\mathrm{T} 2=500 \mathrm{~g} \mathrm{~m}^{-2} ; \mathrm{T} 3=1.000 \mathrm{~g} \mathrm{~m}^{-2} ; \mathrm{T} 4=2.000 \mathrm{~g} \mathrm{~m}^{-2} ; \mathrm{T} 5=3.000 \mathrm{~g} \mathrm{~m}^{-2} ; \mathrm{TC}=$ adubação convencional. Letras diferentes, nas linhas, indicam diferenças significativas entre os tratamentos, pelo teste Tukey $(p=0,05)$.

apresentou os melhores resultados, enquanto o tratamento testemunha (T0) e o tratamento convencional (TC) não diferiram entre si (Tabela 1).

Quanto aos teores de zinco no solo, observouse elevação, conforme aumento das doses de Bokashi, sendo que o tratamento T5 apresentou os melhores resultados. Santos et al. (2008), referindo-se à matéria orgânica e aos micronutrientes, relatam que a formação de complexos com compostos orgânicos reduz a possibilidade da precipitação como óxidos no solo. Desta forma, a complexação (quelação) de zinco, entre outros, por ácidos orgânicos de baixo peso molecular, aumenta a sua disponibilidade, pois o quelato torna-se uma forma de depósito desses elementos. Já em relação aos teores de boro no solo, a adubação orgânica com Bokashi não apresentou eficiência, tendo o tratamento convencional apresentado os melhores resultados (Tabela 1).

A ação da adubação orgânica, em relação ao aumento da disponibilidade de nutrientes, ocorre em função de sua interação com as argilas, formando o complexo argilo-húmico, responsável pela melhoria da capacidade de troca catiônica, especialmente na ação sobre a disponibilidade do fósforo e pela ação estabilizante sobre variações ambientais no solo (Kiehl 1985, Lopes \& Theodoro 1998).

Estes resultados positivos podem ser atribuídos à matéria orgânica presente no Bokashi, a qual possui importante papel na melhoria da fertilidade do solo e nas suas propriedades físicas. Segundo Alleoni \& Beauclair (1995), a matéria orgânica aumenta a capacidade de retenção de água, pois é higroscópica; promove a redução da densidade aparente do solo e o aumento da porosidade total do solo; forma agregados capazes de reduzir a erosão e aumentar a capacidade de absorção do solo; e aumenta a capacidade de troca catiônica, pela ação de micelas húmicas coloidais, com atividade superior à de argilas. Aumenta, ainda, os teores de nitrogênio, fósforo e enxofre, a partir da decomposição e da mineralização da matéria orgânica e promove a redução da fixação do fósforo, pelos óxidos de ferro e alumínio, bloqueando os sítios de fixação com os radicais orgânicos. Forma, também, quelatos solúveis de ferro, manganês, zinco e cobre, disponibilizando-os às raízes, e favorece a atividade microbiológica e adição de novos micro-organismos, diversificando a flora e a microflora do solo. Tudo isso, reagindo no solo, forma húmus, que proporciona um excelente ambiente radicular, mesmo em solos mais pobres, o que aumenta a absorção de nutrientes pelas plantas.

Quanto à diagnose foliar, esta baseia-se na determinação do teor dos nutrientes, em amostras de folhas-diagnósticos. Nesta técnica, ao analisar os elementos minerais contidos em uma folha, ou em parte dela, em determinada idade, deve-se obter 
um diagnóstico do estado nutricional da planta. $\mathrm{Na}$ Tabela 2, encontram-se descritos os resultados das análises dos teores de macro e micronutrientes foliares de Brachiaria brizantha cv. Marandú, submetida a diferentes doses do adubo orgânico Bokashi e adubação convencional.

Pelos resultados das análises químicas foliares, evidenciou-se que o teor de fósforo obtido no tratamento T5 $\left(3.000 \mathrm{~g} \mathrm{~m}^{-2}\right)$ foi superior ao do tratamento convencional (TC), revelando que a adubação fosfatada orgânica pode substituir, com eficiência, a adubação fosfatada convencional, eficiência, esta, atribuída à proteção que a matéria orgânica fornece ao fosfato, contra as reações com minerais de argila e óxidos de ferro. Verificou-se, também, teor acentuado de boro no tratamento convencional, semelhante ao dos tratamentos T4 e T5 (Tabela 2). Tal como o nitrogênio, os teores foliares médios de potássio, cálcio, magnésio, cobre e ferro não diferiram entre os tratamentos estudados. A aplicação de Bokashi também não incrementou a concentração de manganês nas folhas (Tabela 2).

Quanto ao zinco, tem sido observado que a alta concentração de fósforo pode induzir ou aumentar a deficiência de zinco, particularmente em condições de baixa disponibilidade deste elemento (Cakmak \& Marschner 1987). Isto pode ocorrer devido ao fato de o excesso de fósforo aumentar o requerimento fisiológico de zinco (Webb \& Loneragan 1988) e reduzir as taxas de crescimento radicular e de transporte do zinco, da raiz para a parte aérea, ou pela presença do cátion acompanhante da fonte fosfatada, o qual pode inibir a absorção de zinco (Loneragan \& Webb 1993). No entanto, não se observou diferença entre os teores de zinco absorvido pelas folhas da Brachiaria brizantha cv. Marandú.
Avaliando-se os resultados de massa seca total e dos teores de nitrogênio, fósforo e potássio acumulados por grama de massa seca $\left(\mathrm{mg} \mathrm{g}^{-1}\right)$, observou-se que, apesar de haver uma tendência de aumento da massa seca, em resposta ao incremento na aplicação do adubo orgânico Bokashi, não foram observadas variações significativas entre os tratamentos (Tabela 3).

$\mathrm{O}$ acúmulo médio de potássio nas folhas de braquiária não diferiu entre os tratamentos estudados. Entretanto, o acúmulo do nitrogênio e do fósforo foi alterado significativamente $(\mathrm{p}<0,05)$ pelos tratamentos. Com relação ao conteúdo de nitrogênio, verificou-se maior acúmulo nas folhas de braquiária, nas parcelas tratadas com a maior dose do fertilizante orgânico (3.000 $\mathrm{g} \mathrm{m}^{-2}$ - T5), com valor, aproximadamente, $24 \%$ superior ao do tratamento submetido à adubação química convencional (TC). Quanto ao fósforo, também observou-se maior acúmulo nas folhas de braquiária produzidas com $3.000 \mathrm{~g} \mathrm{~m}^{-2} \mathrm{de}$

Tabela 3. Resultados das análises da Produção de Massa Seca Total (MS) e dos teores de NPK acumulados em Brachiaria brizantha $\mathrm{Cv}$. Marandú, em função da adubação do solo com fertilizante orgânico e mineral (Teodro Sampaio, SP, 2008).

\begin{tabular}{ccccc}
\hline Tratamentos & MS $(\mathrm{g}) *$ & N (mg de MS) & P (mg de MS) & $\mathrm{K}^{*}(\mathrm{mg}$ de MS) \\
\hline TC & 183,73 & $3322,84 \mathrm{ab}$ & $391,40 \mathrm{bc}$ & 2534,06 \\
T0 & 157,47 & $2962,22 \mathrm{~b}$ & $326,33 \mathrm{c}$ & 2575,74 \\
T1 & 172,49 & $3325,93 \mathrm{ab}$ & $396,95 \mathrm{bc}$ & 2831,09 \\
T2 & 179,11 & $3315,03 \mathrm{ab}$ & $439,97 \mathrm{abc}$ & 2883,35 \\
T3 & 180,32 & $3551,53 \mathrm{ab}$ & $459,84 \mathrm{ab}$ & 2732,52 \\
T4 & 187,49 & $3940,03 \mathrm{ab}$ & $489,31 \mathrm{ab}$ & 3166,26 \\
T5 & 201,27 & $4374,48 \mathrm{a}$ & $557,47 \mathrm{a}$ & 3384,83 \\
\hline
\end{tabular}

$\mathrm{T} 0=$ testemunha; $\mathrm{T} 1=250 \mathrm{~g} \mathrm{~m}^{-2}$ de Bokashi; $\mathrm{T} 2=500 ; \mathrm{T} 3=1.000 ; \mathrm{T} 4=2.000$ $\mathrm{T} 5=3.000 ; \mathrm{TC}=$ adubação convencional. Diferentes letras indicam diferenças estatísticas significativas entre os tratamentos, pelo teste Tukey $(p=0,05)$. ${ }^{*}$ Sem diferenças significativas $(\mathrm{p}>0,05)$.

Tabela 2. Resultados das análises dos teores foliares de macro e micronutrientes em Brachiaria brizantha cv. Marandú, em função da adubação do solo com fertilizante orgânico e mineral (Teodro Sampaio, SP, 2008).

\begin{tabular}{cccccccccccc}
\hline Tratamento & $\mathrm{N}^{*}$ & $\mathrm{P}$ & $\mathrm{K}^{*}$ & $\mathrm{Ca}^{*}$ & $\mathrm{Mg}^{*}$ & $\mathrm{~S}$ & $\mathrm{~B}$ & $\mathrm{Cu}^{*}$ & $\mathrm{Fe}^{*}$ & $\mathrm{Mn}^{*}$ & $\mathrm{Zn}^{*}$ \\
\hline $\mathrm{T} 0$ & 18,75 & $2,07 \mathrm{c}$ & 16,47 & 2,92 & 4,15 & $1,62 \mathrm{ab}$ & $5,07 \mathrm{abc}$ & 5,50 & 173,80 & 60,00 & 23,50 \\
$\mathrm{~T} 1$ & 19,67 & $2,37 \mathrm{abc}$ & 15,95 & 2,67 & 3,42 & $1,52 \mathrm{~b}$ & $3,07 \mathrm{bc}$ & 4,00 & 213,25 & 64,00 & 25,75 \\
$\mathrm{~T} 2$ & 18,47 & $2,37 \mathrm{abc}$ & 16,87 & 2,32 & 3,22 & $1,57 \mathrm{ab}$ & $2,10 \mathrm{c}$ & 4,75 & 157,75 & 54,25 & 25,50 \\
$\mathrm{~T} 3$ & 19,87 & $2,55 \mathrm{abc}$ & 15,00 & 2,25 & 2,90 & $1,62 \mathrm{ab}$ & $3,62 \mathrm{abc}$ & 5,50 & 228,50 & 53,00 & 23,50 \\
$\mathrm{~T} 4$ & 20,70 & $2,60 \mathrm{ab}$ & 16,62 & 1,87 & 3,47 & $1,67 \mathrm{ab}$ & $7,55 \mathrm{a}$ & 5,75 & 248,00 & 59,00 & 27,25 \\
$\mathrm{~T} 5$ & 21,42 & $2,77 \mathrm{a}$ & 16,80 & 1,90 & 2,82 & $2,02 \mathrm{a}$ & $6,65 \mathrm{ab}$ & 5,00 & 235,00 & 53,50 & 24,50 \\
$\mathrm{TC}$ & 18,12 & $2,22 \mathrm{bc}$ & 13,70 & 2,50 & 3,30 & $1,65 \mathrm{ab}$ & $7,60 \mathrm{a}$ & 5,25 & 231,50 & 60,50 & 24,75 \\
\hline
\end{tabular}

$\mathrm{T} 0=$ testemunha; $\mathrm{T} 1=250 \mathrm{~g} \mathrm{~m}^{-2}$ de Bokashi; $\mathrm{T} 2=500 ; \mathrm{T} 3=1.000 ; \mathrm{T} 4=2.000 ; \mathrm{T} 5=3.000 ; \mathrm{TC}=$ adubação convencional. Letras diferentes indicam diferenças estatisticamente significativas entre os tratamentos, pelo teste Tukey $(\mathrm{p}=0,05)$. ${ }^{*}$ Sem diferenças significativas $(\mathrm{p}>0,05)$. 
composto orgânico, valor, este, aproximadamente $30 \%$ superior ao da adubação química convencional (Tabela 3). Estes resultados estão de acordo com os estudos realizados por Garcia (2005), em canade-açúcar, o qual observou que as fontes orgânicas de fósforo aplicadas isoladamente proporcionaram médias semelhantes de rendimento de massa seca, quando associadas ao adubo mineral, e superiores à aplicação do adubo mineral isoladamente.

Matos et al. (2008) também observaram maior disponibilidade de fósforo, em resposta à aplicação de matéria orgânica, bem como incremento do carbono orgânico total, estabilidade dos agregados em água e elevação do teor de nitrogênio. Estes resultados positivos já eram esperados, uma vez que a presença de radicais orgânicos em decomposição no Bokashi pode ocupar sítios de fixação de fósforo, protegendo este nutriente da reação com os minerais de argila e óxidos de ferro, deixando-o disponível para as plantas. De acordo com Santos et al. (2008), fontes orgânicas podem substituir todo ou parte do fósforo requerido pelas plantas, podendo proporcionar alterações significativas nos atributos químicos do solo, aumentando a disponibilidade de cálcio, nitrogênio e fósforo e os teores de carbono orgânico.

Para garantir a produtividade, altas dosagens de fontes inorgânicas de fósforo são aplicadas ao solo, já que grande parte será complexada. Por outro lado, o uso de fontes orgânicas de fósforo tem um papel fundamental para a vida de micro-organismos, aumentando a capacidade de troca catiônica (CTC) e a mobilidade do fósforo no solo (Novais \& Smyth 1999).

\section{CONCLUSÃO}

O adubo orgânico Bokashi pode substituir, de forma viável, a adubação química convencional da Brachiaria brizantha cv. Marandú, suprindo o solo e a planta com níveis adequados de nutrientes e mantendo a produção de massa seca.

\section{REFERÊNCIAS}

AFIF, E.; BARRÓN, V.; TORRENT, J. Organic matter delays but does not prevent phosphate sorption by Cerrado soils from Brazil. Soil Science, Baltimore, v. 159, n. 3, p. 207-211, 1995.

ALCÂNTARA, P. B.; BUFARAH, G. Plantas forrageiras: gramíneas e leguminosas. São Paulo: Nobel, 1999.
ALLEONI, L. R. F.; BEAUCLAIR, E. G. F. Cana-deaçúcar cultivada após milho e amendoim, com diferentes doses de adubo. Scientia Agricola, Piracicaba, v. 52, n. 3 , p. 409-415, 1995.

ANDRADE, F. V. et al. Adição de ácidos orgânicos e químicos em latossolos e adsorção de fosfato. Revista Brasileira de Ciências do Solo, Viçosa, v. 27, n. 6, p. 10031011, 2003.

CAKMAK, I.; MARSCHNER, H. Mechanism of phosphorus-induced zinc deficiency in cotton. III. Changes in physiological availability of zinc in plants. Physiologia Plantarum, Copenhagen, v. 70, n. 1, p. 13-20, 1987.

COSTA, M. B. B. Nova síntese e novo caminho para a agricultura. São Paulo: Ícone, 1987.

COSTA, N. L. et al. Manejo de pastagens de Brachiaria brizantha cv. Marandú em Rondônia. Macapá: Embrapa, 2001. (Relatório Técnico, n. 33).

DAVID, M. A. et al. Efeito de doses de superfosfato simples e de matéria orgânica sobre o crescimento de mudas de maracujazeiro amarelo. Pesquisa Agropecuária Tropical, Goiânia, v. 38, n. 3, p. 147-152, jul./set. 2008.

EMPRESA BRASILEIRA DE PESQUISA AGROPECUÁRIA (Embrapa). Centro Nacional de Pesquisa de Solos. Manual de métodos de análises de solo. 2. ed. Rio de Janeiro: Embrapa, 1997.

EMPRESA BRASILEIRA DE PESQUISA AGROPECUÁRIA (Embrapa). Centro Nacional de Pesquisa de Solos. Sistema brasileiro de classificação de solos. Rio de Janeiro: Embrapa, 2006.

FORNARI, E. Manual prático de agroecologia. São Paulo: Aquariana, 2002.

GARCIA, J. C. Efeitos da adubação orgânica, associada ou não à adubação química, calagem e fosfatagem, nos rendimentos agrícola e de aguardente teórica da canade-açúcar (Saccharum spp). 2005. 82 f. Tese (Doutorado em Fitotecnia)-Universidade Federal de Lavras, Lavras, 2005.

GUSS, A.; GOMIDE, J. A.; NOVAIS, R. F. Exigências de fósforo para o estabelecimento de quatro espécies de Brachiaria em solos com características físio-químicas distintas. Revista Brasileira de Zootecnia, Viçosa, v. 19, n. 4, p. 278-289, 1990.

HAYNES, R. J. Lime and phosphate in the soil plant system. Advances in Agronomy, San Diego, v. 37, n. 1, p. 249-315, 1984.

HOFFMANN, J. A.; FAQUIM, V.; GUEDES, G. A. A. O Nitrogênio e o fósforo no crescimento da Brachiaria e do colonião em amostras de um latossolo da região do nordeste do Paraná. Revista Brasileira de Zootecnia, Viçosa, v. 19, n. 1, p. 233-243, 1995. 
KIEHL, E. J. Fertilizantes orgânicos. Piracicaba: Agronômica Ceres, 1985

KIRK, G. J. D. A model of phosphate solubilization by organic anion excretion from plant roots. European Journal of Soil Science, Exeter, v. 50, n. 3, p. 369-378, 1999.

LEE, R. B. Selectivity and kinetics of ion uptake by barley plants following nutrient deficieny. Annals of Botany, Oxford, v. 50, n. 4, p. 429-449, 1982.

LOGANATHAN, P.; FERNANDO, W. T. Phosphorus sorption by some coconut growing acid soils of Sri Lanka and its relationship to selected soil properties. Journal of the Science of Food and Agriculture, London, v. 31, n. 7, p. 709-717, 1980.

LONERAGAN, J. F.; WEBB, M. J. Interactions between zinc and other nutrients affecting the growth of plants. In: ROBSON, A. D. (Ed.). Zinc in soil and plants. Dordrecht: Kluwer Academic, 1993. p. 119-134.

LOPES, J. F. P.; THEODORO, V. C. A. Apostila de criação de minhocas e criação de húmus. Lavras: UFLa/ Faepe, 1998.

MALAVOlTA, E.; VITTI, G. C.; OLIVEIRA, S. A. Avaliação do estado nutricional das plantas: princípios e aplicações. 2. ed. Piracicaba: Potafos, 1997.

MATOS, F. V. Estabilidade de agregados e distribuição de carbono e nutrientes em argissolos sob adubação orgânica e mineral. Pesquisa Agropecuária Brasileira, Brasília, DF, v. 43, n. 9, p. 1221-1230, 2008.
NOVAIS, R. F.; SMYTH, T. T. Fósforo em solo e planta em condições tropicais. Viçosa: UFV, 1999.

NOVAIS, R. F.; BRAGA, J. M.; MARTINS FILHO, C.A. Efeito do tempo de incubação do fosfato de Araxá em solos sobre o fósforo disponível. Revista Brasileira de Ciência do Solo, Viçosa, v. 4, n. 1, p. 153-155, 1980.

RAIJ, B. van et al. (Eds.). Análise química para avaliação da fertilidade de solos tropicais. Campinas: IAC, 2001.

RUFTY, T. W. et al. Phosphate regulation of nitrate assimilation in soybean. Journal of Experimental Botany, Oxford, v. 44, n. 5, p. 879-891, 1993.

SANTOS, G. A. et al. Fundamentos da matéria orgânica no solo: ecossistemas tropicais e subtropicais. 2. ed. Porto Alegre: Metrópole, 2008.

SCHJORRING, J. K. Nitrate and ammonium absorption by plants growing at a sufficient or insufficient level of phosphorus in nutrient solution. In: LAMERS, H. (Ed.). Fundamental ecological and agricultural aspects of nitrogen metabolism in higher plants. Dordrecht: Martinus Nijhoff, 1996. p. 53-58.

WEBB, M. J.; LONERAGAN, J. F. Effect of zinc deficiency on growth, phosphorus concentration, and phosphorus toxicity of wheat plants. Soil Science Society of America Journal, Madison, v. 52, n. 6, p. 1676-1680, 1988. 